\title{
ANÁLISE SOBRE A INCLUSÃO E PERMANÊNCIA DOS ALUNOS COM DEFICIÊNCIA EM UMA UNIVERSIDADE DO SUL DE MINAS GERAIS
}

\author{
ANÁLISIS SOBRE LA INCLUSIÓN Y PERMANENCIA DE ESTUDIANTES CON \\ DISCAPACIDAD EN UNA UNIVERSIDAD DEL SUR DE MINAS GERAIS
}

\author{
ANALYSIS ON THE INCLUSION AND PERMANENCE OF STUDENTS WITH \\ DISABILITIES IN A SOUTH UNIVERSITY OF MINAS GERAIS
}

\author{
Aurélia TEODORO DA CRUZ ${ }^{1}$ \\ Paloma Alinne ALVES RODRIGUES ${ }^{2}$
}

\begin{abstract}
RESUMO: A inclusão de alunos com deficiência tem se apresentado como um desafio diário para as instituições de ensino, em especial, nas universidades. Diante disso, este trabalho teve por objetivo investigar e analisar o processo de inclusão e permanência dos alunos com deficiência em uma instituição de ensino superior localizada no sul de Minas Gerais. O trabalho configura-se como uma pesquisa com abordagem qualitativa e com características de estudo de caso. Para a coleta dos dados, os alunos com deficiência foram convidados a responder um questionário. Por meio da análise, foi possível constatar que se faz necessário trabalhar com a comunidade ações relacionadas a empatia e aceitação das diferenças e com os professores, formações que contemplem práticas inclusivas.
\end{abstract}

PALAVRAS-CHAVE: Inclusão. Ensino Superior. Permanência.

RESUMEN: La inclusión de estudiantes con discapacidades se ha presentado como un desafio diario para las instituciones educativas, especialmente en las universidades. Por lo tanto, este trabajo tuvo como objetivo investigar y analizar el proceso de inclusión y permanencia de estudiantes con discapacidades en una institución de educación superior ubicada en el sur de Minas Gerais. El trabajo se configura como una investigación con enfoque cualitativo y con características de estudio de caso. Para la recolección de datos, se les pidió a los estudiantes con discapacidades que respondieran un cuestionario. A través del análisis, se descubrió que es necesario trabajar con las acciones comunitarias relacionadas con la empatía y la aceptación de las diferencias y con los docentes, capacitación que incluye prácticas inclusivas.

PALABRAS CLAVE: Inclusión. Enseñanza superior. Permanencia.

ABSTRACT: The inclusion of students with disabilities has been a daily challenge for educational institutions, especially in universities. Therefore, this study aimed to investigate and analyze the process of inclusion and permanence of students with disabilities in a higher education institution located in the South of Minas Gerais. The work is configured as a

\footnotetext{
${ }^{1}$ Universidade Federal de Itajubá (UNIFEI), Itabira - MG - Brasil. Acadêmica do curso de Ciências Biológicas. ORCID: https://orcid.org/0000-0003-0174-2324. E-mail: aurelia.cruz@unifei.edu.br

${ }^{2}$ Universidade Federal de Itajubá (UNIFEI), Itabira - MG - Brasil. Professora do Instituto de Física e Química (IFQ). Coordenadora do grupo de pesquisa "Núcleo de Estudos em Formação Docente, Tecnologias e Inclusão (NEFTI)". ORCID: https://orcid.org/0000-0001-8186-1985. E-mail: palomaraap@unifei.edu.br
} 
research with a qualitative approach and with case study characteristics. For data collection, students with disabilities were asked to respond to a questionnaire. Through the analysis it was possible to verify that it is necessary to work with the community actions related to empathy and acceptance of the differences; and with teacher educations that contemplate inclusive practices.

KEYWORDS: Inclusion. Higher education. Permanence.

\section{Introdução}

De acordo com dados de 2011 da Organização Mundial de Saúde (OMS), estima-se que cerca de 1 bilhão de pessoas viva com algum tipo de deficiência e precise lidar, dia após dia, com obstáculos físicos e sociais que as impedem de viver de forma plena e autônoma (UNITED NATIONS, 2017). Uma breve análise da história do atendimento às pessoas com deficiência no Brasil e no mundo mostra que as ações de amparo a esse público iniciaram-se há aproximadamente dois séculos de forma rudimentar e equivocada, e que, ainda hoje, não atingiram plenamente o objetivo de proporcionar melhor qualidade de vida e maiores oportunidades a essas pessoas.

Conforme mostra Lanna Júnior (2010), em meados do século XIX, instituições voltadas para pessoas com deficiência começaram a funcionar no Brasil, por exemplo, o "Hospício Don Pedro II", um hospital "destinado privativamente para o tratamento de alienados", situado na cidade do Rio de Janeiro, no ano de 1852. Nos anos de 1854 e 1856 , tivemos ainda a abertura do "Imperial Instituto dos Meninos Cegos" e do "Imperial Instituto dos Meninos Surdos-Mudos". A partir de então, a evolução de tais institutos ocorreu de forma lenta e novas ações foram tomadas no século XX com a criação de associações como Sociedades Pestalozzi (1932) e Associação de Pais e Amigos dos Excepcionais - Apae (1954) (LANNA JÚNIOR, 2010).

A partir dos anos 1960, verifica-se no Brasil uma mudança de comportamento político com relação às pessoas com deficiência, quando as leis começam a especificar que os direitos que propõem se destinam a todos os brasileiros, sem distinção. Um exemplo é a Lei 4.024/1961, intitulada Lei de Diretrizes e Bases da Educação (LDB), a qual recomendava que a educação especial fosse integrada ao Sistema Regular de Ensino e ressaltava que ela é um direito de todos (BAPTAGLIN; SOUZA, 2011).

Ainda que de forma rudimentar, a primeira versão da LDB, que tratava as pessoas com deficiência por "excepcionais", deixava claro que esses alunos deviam, "na medida do possível". ser enquadrados no sistema geral de educação a fim de se integrar à comunidade. 
Disponibilizava, ainda, recursos financeiros em forma de bolsas e subvenções para iniciativas privadas que atendessem tais alunos de maneira eficiente.

No entanto, é evidente, por meio da própria legislação aplicada na época, que os processos de seleção de alunos para as instituições de ensino superior passavam longe do ideal inclusivo, que, até então, engatinhava em meio a tantos entraves culturais. Na Lei 5.540/1968, que fixava as normas para o funcionamento do ensino superior, o artigo 21 informava:

O concurso vestibular, referido na letra $a$ do artigo 17, abrangerá os conhecimentos comuns às diversas formas de educação do segundo grau sem ultrapassar este nível de complexidade para avaliar a formação recebida pelos candidatos e sua aptidão intelectual para estudos superiores (BRASIL, 1968, [s.p.]).

Cabral (2018) destaca o quanto ficava explícita a segregação que essa metodologia causava, visto que em toda a sua escolarização o aluno com deficiência se deparava com ensinamentos reduzidos e fragmentados, em face do pouco ou inexistente preparo das escolas que frequentava. Assim, tornava-se impossível concorrer às vagas disponíveis no ensino superior, pois os alunos estariam sempre em desvantagem intelectual, de acordo com os preceitos do artigo em questão.

As próximas décadas trouxeram avanços lentos, porém sucessivos, rumo à equiparação de direitos e de oportunidades às pessoas com deficiência. Foram realizados discussões, estudos e experiências em países como Alemanha, com sua Integrationspädagogik (Integração Pedagógica), com o objetivo de criar políticas e ações para permitir a inclusão dessas pessoas e garantir sua efetiva participação na sociedade (BEYER, 2003).

A Declaração sobre os Direitos das Pessoas com Deficiência, proclamada pela Assembleia Geral da Organização das Nações Unidas (ONU), em 9 de dezembro de 1975, é um marco do reconhecimento mundial da importância de desmistificar esse grupo e fornecer condições de convivência justa e o mais autossuficiente possível em sociedade. No Brasil, a Constituição de 1988, promulgada em 5 de outubro daquele ano, traz em seu artigo 205, de forma clara e irrefutável, que:

A educação, direito de todos e dever do Estado e da família, será promovida e incentivada com a colaboração da sociedade, visando ao pleno desenvolvimento da pessoa, seu preparo para o exercício da cidadania e sua qualificação para o trabalho (BRASIL, 1988, [s.p.], grifo nosso).

Assim, formaliza-se que todas as pessoas têm direito à educação eficiente e de caráter igualitário e, ainda, que o Estado tem o dever de prover meios para que todos usufruam 
totalmente desse direito e dos benefícios advindos dela. A partir de então, alterações na legislação foram feitas para que os direitos das pessoas com deficiência fossem igualados aos do restante da população.

Cabe destacar que, o artigo 2. ${ }^{\circ}$ da Lei 13.146, de 6 de julho de 2015, conhecida como Estatuto da Pessoa com deficiência, define que essas pessoas possuem algum "impedimento de longo prazo de natureza física, mental, intelectual ou sensorial, o qual, em interação com uma ou mais barreiras, pode obstruir sua participação plena e efetiva na sociedade em igualdade de condições com as demais pessoas" (BRASIL, 2015, [s.p.]).

Esse processo de inclusão das pessoas com deficiência se embasa primeiramente em seu acesso ao ensino de qualidade, desde seu primeiro contato com a escola. Sabe-se que uma sólida formação escolar é instrumento facilitador na busca por melhores condições sociais para qualquer pessoa. Assim, todos os esforços se concentraram inicialmente em permitir que as pessoas com deficiência usufruam do ensino regular e de qualidade, com os demais. Então, nos últimos anos, a inclusão desses alunos no ensino superior também passou a ser foco de ações, com a abertura de reserva de vagas nas universidades federais do País, por meio da Lei 13.409/2016, que alterou o sistema de reserva preexistente que contemplava apenas alunos considerados de baixa renda e, ainda, os autodeclarados pretos, pardos e indígenas.

A partir da promulgação dessa lei, os alunos com deficiência passaram a disputar as vagas reservadas e as de ampla concorrência, considerando suas características de reserva, num percentual compatível com o da população local da cidade onde está instalada a instituição de ensino. Logo, percebe-se que há um respaldo significativo na legislação para que as pessoas com deficiência tenham oportunidades de estudo iguais às dos demais alunos. No entanto, o que se vê na realidade das universidades públicas do País é que a quantidade de alunos com essas características é ínfima a ponto de não serem utilizadas todas as vagas disponíveis para tais alunos e, o que é pior, se sua entrada no ensino superior é garantida, a sua permanência é uma incógnita (SIQUEIRA; RODRIGUES, 2016).

Portanto, faz-se necessário que essas instituições não apenas forneçam vagas para esses alunos, mas meios para que eles permaneçam em seu quadro de discentes pelo tempo necessário à sua formação, com condições de executar todas as suas atividades de forma plena e o mais autossuficiente possível.

Por vezes, os prédios das instituições públicas foram construídos há décadas e não atendem aos preceitos atuais de projetos que levam em consideração o fato de que eles podem ser frequentados por pessoas com os mais variados tipos de deficiência ou mobilidade reduzida e que, por esse motivo, sua construção deve ser embasada em normas técnicas que atendem a todo tipo de público. Assim, é possível encontrar problemas como escadas 
íngremes, múltiplos andares sem elevador, pisos deformados ou escorregadios, falta de sinalização e portas estreitas.

Na rotina acadêmica, professores sem formação prévia para lidar com a vasta gama de deficiências existentes encabeçam uma lista de entraves que parece não ter fim. A falta de didática para lidar com alunos que, devido à deficiência auditiva, não escutam as explicações, que não enxergam os slides do conteúdo das aulas ou que simplesmente possuem dificuldade de compreender o conteúdo de forma rápida é parte da rotina dentro de salas que abrigam alunos com deficiência.

Por último, e não menos significativo, temos a falta de conhecimento dos demais alunos em lidar com a diferença e que, por vezes, segregam os alunos com deficiência, privando-lhes do acolhimento, que é fundamental no desenvolvimento pleno de suas capacidades dentro do ambiente universitário. Partindo desse pressuposto, considera-se a necessidade de realizar esforços não só para a inclusão deles nas universidades e institutos federais, mas também para que sua permanência seja alicerçada no pleno compartilhamento de conhecimentos e experiências válidas em seu crescimento pessoal, acadêmico e profissional.

Tendo em vista esse cenário, Pereira (2007) considera importante que se abra um espaço para que se utilizem de novas concepções e significados, suscitando adaptações, mudanças e inovações adequadas às novas demandas sociais das universidades federais. Diante do exposto, o objetivo deste artigo é analisar o processo de inclusão educacional e permanência dos discentes com deficiência da Universidade Federal de Itajubá (Unifei), contemplando aspectos da rotina acadêmica, a forma como sua deficiência afeta essa rotina e quais as expectativas diante desse cenário.

\section{Aspectos Metodológicos}

A pesquisa realizada neste trabalho é do tipo qualitativa, a qual permite a verificação de importantes aspectos relacionados à condição específica de sujeito, o que não se faz possível diante de uma abordagem quantitativa (SEVERINO, 2013). A investigação foi realizada nos dois campi de uma Universidade Federal no Estado de Minas Gerais, com alunos ingressantes do ano de 2018, matriculados pelo regime de cotas, na fração destinada às pessoas com deficiência. Além disso, o tipo de pesquisa caracteriza-se como estudo de caso, visto que nele "o pesquisador geralmente utiliza uma variedade de dados, coletados em diferentes momentos, por meio de variadas fontes de informação. Tem como técnicas fundamentais de pesquisa a observação e a entrevista" (GODOY, 1995). 
Os dados foram levantados no período de setembro a outubro de 2018 com os dez alunos com deficiência declarada no momento da matrícula. Cada qual recebeu um questionário com quatorze questões abertas que foram encaminhadas via e-mail. Conforme argumenta André (2005), estudos desse tipo são valorizados "pela sua capacidade heurística, isto é, por jogarem luz sobre o fenômeno estudado, de modo que o leitor possa descobrir novos sentidos, expandir suas experiências ou confirmar o que já sabia”. A autora ainda salienta que "espera-se que o estudo de caso ajude a compreender a situação investigada e possibilite a emersão de novas relações e variáveis, ou seja, que leve o leitor a ampliar suas experiências" (ANDRÉ, 2005, p. 34). Portanto, para a coleta de dados optou-se pela entrevista estruturada.

Por preceitos éticos previstos na alínea $i$ do item 2, parte III, da Resolução 466/2012 do Conselho Nacional de Saúde, os procedimentos que asseguram a confidencialidade e a privacidade dos entrevistados foram seguidos. Logo, os dados de identificação destes foram omitidos e eles foram identificados por codificação, definidos como A1 (aluno 1), A2 (aluno 2), A3 (aluno 3) e assim por diante (BRASIL, 1996, [s.p.]).

Os dados obtidos foram analisados de acordo com a metodologia indicada por Bardin (2016), com a construção de categorias que permitiram a interpretação dos dados fornecidos pelas respostas dos alunos. Esses processos também podem ser chamados de "Inventário" em que os elementos advindos das respostas são isolados - e "Classificação" - em que essas mensagens são organizadas (BARDIN, 2016), e visam extrair dados das respostas obtidas para, enfim, visualizar seu significado. Feito isso, os dados foram categorizados de modo a organizá-los por significados semelhantes, os quais foram relevantes no desenvolvimento do tema e permitiram observar de forma homogênea as percepções dos entrevistados acerca de cada tópico abordado.

Diante disso, elaboraram-se as quatro categorias de análise: convivência com professores - a qual tinha o intuito de verificar a forma de atendimento das pessoas com deficiência por parte dos professores; convivência com colegas - pretendia verificar de que maneira os alunos com deficiência são recebidos por seus pares de curso; acessibilidade do campus - compreender de que modo os aspectos físicos do campus influenciavam na acessibilidade desse público; motivação em permanecer na universidade - visava fornecer um vislumbre dos fatores que influenciaram a permanência ou não de alunos com deficiência na universidade.

De um efetivo de 6.590 alunos, divididos entre os dois campi, 14 foram matriculados como pessoa com deficiência e apenas 6 responderam à pesquisa. Um dos alunos 
matriculados pela reserva de vagas para pessoas com deficiência desistiu do curso. Os sujeitos da pesquisa estão caracterizados conforme descrito na Tabela 1.

Tabela 1 - Levantamento de alunos por campus

\begin{tabular}{c|c|c|c} 
& Campus Itabira & Campus Itajubá & Total \\
\hline Matriculados & 1.754 & 4.836 & 6.590 \\
\hline Ingressantes & 451 & 1.093 & 1.544 \\
\hline Desistente (PcD) & - & 1 & - \\
\hline Alunos Convidados & 4 & 10 & 14 \\
\hline Respostas Recebidas & 1 & 5 & 6 \\
\hline
\end{tabular}

Fonte: A Autora.

Com relação à deficiência e sexo das pessoas que responderam às perguntas, temos o cenário disponível na Tabela 2.

Tabela 2 - Levantamento de gênero e deficiência

\begin{tabular}{c|c|c|c}
\hline & $\begin{array}{c}\text { Deficiência } \\
\text { Auditiva }\end{array}$ & Deficiência Visual & Deficiência Física \\
\hline Homem & 1 & 3 & 0 \\
\hline Mulher & 1 & 0 & 1 \\
\hline
\end{tabular}

Fonte: A Autora

\section{Análise dos Dados}

\section{Convivência com Professores}

A análise dos dados revelou que quatro dos seis alunos entrevistados sentiram dificuldades no relacionamento com os professores por conta de sua deficiência. O aluno A4 destacou, por exemplo, que, apesar de declarar no momento da matrícula a necessidade de atendimento diferenciado, sua solicitação não foi atendida por alguns professores.

A4: "Só dois professores que no momento da aplicação da prova eles me entregaram a prova em um tamanho que eu tive um pouco de dificuldade para realizar a prova (sendo que no dia de minha matrícula foi pedida uma prova com uma fonte maior)".

Pelo relato do aluno A2, tem-se que muitas vezes a inclusão é entendida de forma equivocada pelos professores, que tratam os alunos com deficiência com educação, porém não 
compreendem o tipo de atendimento necessário para que ele possa realizar suas atividades em sala de maneira plena:

A2: “[...] o professor até era educado, mas não compreendia minha limitação".

As ações de inclusão nem sempre são totalmente compreendidas e geralmente passam por equívocos como o relatado, quando, em vez do fornecimento de condições plenas para execução de suas atividades universitárias, o aluno é apenas tratado com polidez por seus docentes sem ter, de fato, suas necessidades educacionais atendidas.

O aluno A3 relatou que inicialmente houve dificuldade de enxergar o quadro da sala, porém o professor conseguiu contorná-la com uma atitude simples que permitiu que ele acompanhasse a matéria sem maiores dificuldades, o que demonstra que nem sempre são necessárias grandes mudanças para que o processo inclusivo ocorra.

A3: "Sim, por conta de não enxergar de longe tenho dificuldade em ler no quadro, mais isso foi resolvido (professor imprimiu a matéria) facilitou bastante".

No entanto, nem todos os relatos dão conta apenas de dificuldades, conforme mostra o aluno A6:

A6: "Todos os professores que eu tenho falam auto [SIC] e explicam bem, facilitando o meu entendimento".

Apesar da ocorrência de algumas falhas no fornecimento de condições de acessibilidade adequada aos alunos, o depoimento do aluno A6, que possui deficiência auditiva, mostra que os professores adotam posturas facilitadoras nas aulas e reconhece a tentativa do docente em auxiliá-lo no entendimento do conteúdo ensinado, como demonstra o relato anterior.

\section{$>$ Convivência com Colegas}

No tocante à convivência com os colegas, os relatos dos alunos são equilibrados. Três dos entrevistados mencionaram não enfrentar nenhuma dificuldade, enquanto os outros três alunos viveram alguma situação de ordem comportamental como bullying, falta de compreensão ou ausência de disposição dos colegas em promover uma convivência saudável.

Os dados também demonstraram um incômodo significativo que esse tipo de situação pode gerar no aluno com deficiência, como mostra o relato do aluno A1: 
A1: "Sim. A turma não entende que tenho a limitação a qual preciso assentar a frente [sic] e nem sempre entendem, acham que estou aproveitando da situação. A sensação é ruim”.

Esse relato demonstra o quanto a dinâmica do meio acadêmico interfere no bem-estar dos alunos com deficiência, visto que, a partir do momento que o aluno se sente incomodado pela reação dos colegas às suas necessidades, acaba se retraindo e negando o convívio com a turma para evitar situações como as referidas pelo aluno A2:

A2: "Sim. Tenho comigo que foi mais por falta de consciência e maturidade dos colegas algumas falas que ouvi, bem como algumas atitudes".

A questão emocional dos estudantes é um fator importante e de grande impacto em sua tomada de decisão. Ciente disso, a universidade possui o Núcleo de Acessibilidade e Inclusão, responsável por diversas ações informativas e formativas que visam desmistificar o tema inclusão, trazendo à comunidade eventos na temática inclusiva que proporcionam a disseminação do conhecimento a respeito do tema, bem como fornecem ferramentas para que pessoas com deficiência tenham melhores oportunidades, dentro e fora da universidade, com o intuito de mitigar situações como as relatadas pelo aluno A6:

A6: "Sim, me sinto excluído de um grupo, pois não consigo ouvir muito bem, e eles acabam se irritando quando eu digo que não entendi e peço para repetir".

O apoio da universidade é de extrema importância para que a comunidade se conscientize da necessidade de inclusão, bem como para que os alunos com deficiência, que dela fazem parte, tenham a oportunidade de experienciar a vida universitária de forma plena e compatível com o que é vivenciado por seus colegas.

\section{$>$ Acessibilidade do Campus}

No que concerne à estrutura física da Universidade, quatro dos seis alunos entrevistados relataram não ter problemas com a acessibilidade no campus. Por outro lado, dois alunos salientaram ter vivenciado algum tipo de dificuldade com equipamentos e sinalização da universidade. O entrevistado A2 teve problemas com equipamento usado em sala de aula, situação que foi prontamente contornada, conforme mostra seu relato:

A2: "Sim, a prancheta de desenho, porém trocaram ela por uma antiga que já possuía uma régua fixa (minha dificuldade era de segurar a régua)”.

A3 relatou que sentiu dificuldade na identificação de salas por conta das placas que apresentam escrita em fontes de tamanho pequeno. Esse detalhe, que pode passar 
despercebido pela maioria dos alunos, dificulta a leitura por pessoas com deficiência visual, mas pode ser facilmente resolvido pela instituição com a troca por placas de sinalização com fontes maiores, o que já tem sido feito na entrada de todos os prédios dos campi com placas grandes que facilitam a identificação dos locais. Apesar do contratempo, o aluno afirma que consegue lidar com a situação de forma "tranquila", conforme seu relato:

A3: "Único problema foi para achar as salas, devido os números e letras serem pequenos (mais é tranquilo)".

Os campi ainda oferecem piso tátil alerta e direcional para o público com baixa acuidade visual ou cegueira, por toda a área de circulação. Uma ferramenta simples que auxilia na locomoção dessas pessoas e evita problemas graves de segurança, visto que os direciona para locais corretos de circulação. Essas pequenas modificações na estrutura física das universidades são primordiais para que a permanência de pessoas com deficiência no ensino público superior se dê com qualidade e devido respeito à inclusão.

\section{Motivação em Permanecer na Universidade}

De forma geral, a maioria dos entrevistados acredita que existem dificuldades para permanência no ensino superior, e cinco dos seis entrevistados declararam reconhecer ou vivenciar essas dificuldades. Alunos como A4 salientaram como motivação para essa situação a falta de preparo das instituições para atuar com sujeitos com deficiência, conforme deixa claro em sua resposta:

A4: "A universidade não está totalmente preparada para receber alunos com deficiência".

Ainda que os alunos com deficiência matriculados no ano de 2018 relatem as dificuldades encontradas, é possível verificar que as ações de inclusão se tornaram uma realidade tanto na estrutura física quanto na funcional dos campi, melhorando o acesso dos alunos e ajudando em seu processo de permanência na universidade. Os reflexos dessas ações podem ser sentidos pelos usuários, como relata o aluno A6 quando questionado sobre as dificuldades de permanência no ensino superior, ao salientar que não as enfrenta no campus onde estuda:

A6: "Sim, há dificuldades, mas creio que não é o meu caso".

A Unifei disponibiliza aos alunos atendimento multidisciplinar composto de acompanhamento psicossocial, apoio pedagógico e atendimento psicológico por meio da 
Diretoria de Assuntos Comunitários e Estudantis (Dace), com ações que têm por finalidade promover aos alunos a igualdade de oportunidades com iniciativas que combatem a evasão. Apesar dos esforços empreendidos pela instituição, ainda há um longo caminho a ser percorrido para que todos sejam atendidos, conforme aponta o aluno A1:

A1: "Sim, pois muitos se desmotivam por uma série de fatores. Acho que deveria ter mais de um profissional psicólogo para fazer acompanhamento".

Não obstante as críticas aos procedimentos de atendimento aos alunos com deficiência, a Unifei possui uma estrutura de atendimento que é constantemente ampliada e, como citado anteriormente, conta com um Núcleo de Acessibilidade e Inclusão que, além de monitorar as ações inclusivas dos campi, fomenta eventos de cunho educativo para conscientizar a comunidade - tanto estudantil quanto de moradores - da importância das ações inclusivas para as pessoas com deficiência e também para nossa sociedade como um todo.

\section{Considerações finais}

Percebe-se pelas respostas recebidas que, quando falamos de ações de incentivo à permanência de alunos com deficiência nas universidades federais, ainda há um longo caminho a percorrer, principalmente no que tange ao apoio psicológico desses alunos e à conscientização de todos os que com eles convivem no meio acadêmico.

A cultura de aceitação e amparo ainda precisa ser trabalhada de forma a tornar efetiva a convivência com os colegas e professores. A universidade precisa fornecer, além das questões físicas, meios psicológicos e emocionais para que os alunos consigam aproveitar sua jornada acadêmica de forma mentalmente saudável.

Por meio das sugestões dos entrevistados é possível perceber que demandas básicas como formação de professores para lidar com o tema ainda são necessárias, assim como a organização de uma equipe multidisciplinar para atendimento dos alunos com deficiência e realização de reuniões individuais esporádicas para analisar e discutir suas demandas.

Observa-se também que a alteração na Lei 13.409/16 trouxe um grande avanço ao possibilitar que estes alunos adentrassem o ensino superior. Agora os esforços precisam ser voltados para que sua permanência ocorra de forma a possibilitar o maior aproveitamento possível de suas habilidades, assim como do que a universidade tem a oferecer a todos os alunos. 


\section{Referências}

ANDRÉ, Marli Eliza Dalmazo Afonso de. Estudo de caso em pesquisa e avaliação educacional. Brasília: Liberlivros, 2005.

BAPTAGLIN, Leila Adriana; SOUZA, Karina Malon. Inclusão na educação superior: uma revisão das produções atuais. 2011. p. 1-10. Disponível em:

http://www.unifra.br/eventos/sepe2012/Trabalhos/5325.pdf. Acesso em: 17 abr. 2018.

BARDIN, Laurence. Análise de conteúdo. Tradução Luis Antero Reto e Augusto Pinheiro. São Paulo: Edições 70, 2016.

BEYER, Hugo Otto. Integração e inclusão escolar: reflexões em torno da experiência alemã. Integração e inclusão escolar - Ensaio. Rev. Bras. Ed. Esp., Marília, v. 8, n. 2, p. 157-168, jul./dez. 2002. Disponível em:

http://www.socialiris.org/antigo/imagem/boletim/arq4d59d0a4b45ad.pdf. Acesso em: 22 maio 2018.

BEYER, Hugo Otto. A educação inclusiva: incompletudes escolares e perspectivas de ação. Revista Cadernos de Educação Especial, Santa Maria, n. 22, p. 1-9, 2003. Disponível em: http://coralx.ufsm.br/revce/ceesp/2003/02/r3.htm. Acesso em: 22 maio 2018.

\section{BRASIL. Lei 5.540/1968. Fixa normas de organização e funcionamento do ensino} superior e sua articulação com a escola média.

BRASIL. Constituição da República Federativa do Brasil: D.O. 5 de outubro de 1988. Disponível em: www.mec.gov.br/legis/default.shtm. Acesso em: 22 maio 2018.

BRASIL. Lei de Diretrizes e Bases da Educação Nacional - Lei n. ${ }^{\circ}$ 9.394/1996. Brasília, 2017. Disponível em: http://www.planalto.gov.br/ccivil_03/leis/19394.htm. Acesso em: 23 abr. 2018.

BRASIL. Portaria n. ${ }^{\circ}$ 3.128/2008. Define que as Redes Estaduais de Atenção à Pessoa com Deficiência Visual sejam compostas por ações na atenção básica e Serviços de Reabilitação Visual. Diário Oficial da União, Brasília, DF, 24 de dezembro de 2008. Disponível em: http://bvsms.saude.gov.br/bvs/saudelegis/gm/2008/prt3128_24_12_2008.html. Acesso em: 8 out. 2018.

BRASIL. Censo Demográfico 2010. Principais resultados - População residente por tipo de deficiência permanente, 2010. Disponível em: https://www.ibge.gov.br/estatisticasnovoportal/sociais/saude/9662-censo-demografico-2010.html?edicao=9749\&t=destaques . Acesso em: 8 out. 2018.

BRASIL. Lei n. 12.711/2012. Dispõe sobre o ingresso nas universidades federais e nas instituições federais de ensino técnico de nível médio e dá outras providências. Diário Oficial da União, Brasília, DF, 29 de agosto de 2012. Disponível em: http://www.planalto.gov.br/ccivil_03/_ato2011-2014/2012/lei/112711.htm. Acesso em: 31 mar. 2018.

BRASIL. Resolução CNS n.o 466, de 12 de dezembro de 2012. Brasília, 2012. Disponível em: http://bvsms.saude.gov.br/bvs/saudelegis/cns/2013/res0466_12_12_2012.html. Acesso em: 23 jul. 2018. 
BRASIL. Lei n. ${ }^{\circ}$ 13.146/2015. Institui a Lei Brasileira de Inclusão da Pessoa com Deficiência (Estatuto da Pessoa com Deficiência). Diário Oficial da União, Brasília, DF, 6 de julho de 2015. Disponível em: http://www.planalto.gov.br/ccivil_03/_ato20152018/2015/lei/L13144.htm. Acesso em: 31 mar. 2018.

BRASIL. Lei n. ${ }^{\circ} 13.409 / 2016$. Altera a Lei n. ${ }^{\circ} 12.711$, de 29 de agosto de 2012, para dispor sobre a reserva de vagas para pessoas com deficiência nos cursos técnico de nível médio e superior das instituições federais de ensino. Diário Oficial da União, Brasília, DF, 28 de dezembro de 2016. Disponível em: http://www.planalto.gov.br/ccivil_03/_ato20152018/2016/lei/L13409.htm. Acesso em: 31 mar. 2018.

CABRAL, Leonardo Santos Amâncio. Políticas de ações afirmativas, pessoas com deficiência e o reconhecimento das identidades e diferenças no ensino superior brasileiro. Arquivos Analíticos de Políticas Educativas, v. 26, n. 57, 2018. Disponível em: http://dx.doi.org/10.14507/epaa.26.3364. Acesso em: 23 abr. 2018.

GODOY, Arilda Schmidt. Pesquisa qualitativa: tipos fundamentais. Revista de Administração de Empresas, v. 35, n. 3, p. 20-29, jun. 1995. ISSN 0034-7590. Disponível em: http://www.scielo.br/scielo.php?script=sci_arttext\&pid=S003475901995000300004\&lng=pt\&nrm=iso. Acesso em: 15 ago. 2018.

LANNA JÚNIOR, Mário Cléber Martins (Comp.). História do Movimento Político das Pessoas com Deficiência no Brasil. Brasília: Secretaria de Direitos Humanos, Secretaria Nacional de Promoção dos Direitos da Pessoa com Deficiência, 2010.

PEREIRA, Marilú Mourão. Inclusão e universidade: análise de trajetórias acadêmicas na Universidade Estadual do Rio Grande do Sul. 2007. 216f. Dissertação (Mestrado em Educação) - Universidade Federal do Rio Grande do Sul, Porto Alegre, 2007. Disponível em: http://hdl.handle.net/10183/14671. Acesso em: 2 abr. 2018.

SEVERINO, Antônio Joaquim. Metodologia do trabalho científico [livro eletrônico Edição Kindle]. São Paulo: Cortez, 2013.

SILVA, Vera Lucia Ruiz Rodrigues da. Educação especial no Paraná: a coexistência do atendimento público e privado nos anos de 1970 e 1980. Curitiba: Appris Editora, 2018.

SIQUEIRA, Andressa Moreira; RODRIGUES, Paloma Alinne Alves. Análise das pesquisas de educação inclusiva em periódicos relacionados ao ensino de ciências. In: VII CONGRESSO BRASILEIRO DE EDUCAÇÃO ESPECIAL 2016, Anais... 14 p. Acesso em: 06 ago. 2018.

UNIFEI. Dados gerais - Números Unifei. Disponível em: https://unifei.edu.br/apresentacao/unifei-em-numeros/dados-gerais/+\&cd=1\&hl=ptBR\&ct=clnk\&gl=br. Acesso em: 11 out. 2018.

UNITED NATIONS - DIVISION FOR SOCIAL POLICY AND DEVELOPMENT DISABILITY. Division for Social Policy and Development Disability. 2017. Disponível em: https://www.un.org/development/desa/disabilities/resources/monitoring-and-evaluation-ofinclusive-development.html. Acesso em: 23 abr. 2018. 


\section{Como referenciar este artigo}

CRUZ, Aurélia Teodoro da; RODRIGUES, Paloma Alinne Alves. Análise sobre a inclusão e permanência dos alunos com deficiência em uma universidade do sul de minas gerais. Doxa: Rev. Bras. Psico. e Educ., Araraquara, v. 21, n. 2, p. 241-254, jul./dez. 2019. e-ISSN: 25948385. DOI: https://doi.org/10.30715/doxa.v21i2.13091

Submetido em: 20/02/2019

Aprovado em: 20/07/2019

Publicado em: 01/08/2019 